\title{
Oral Drops, Emulsion Dosage Form
}

National Cancer Institute

\section{Source}

National Cancer Institute. Oral Drops, Emulsion Dosage Form. NCI Thesaurus. Code C149707.

Liquid, usually multidose preparation consisting of an emulsion intended for oral use. The preparation is administered in small volumes by means of a suitable measuring device such as a dropper, pipette or oral syringe capable of accurate dosing of the emulsion. The measured dose may be diluted in water or another suitable liquid before swallowing. 